\title{
Laboreal
}

Volume $16 \mathrm{~N}^{\circ} 2$ | 2020

Programa de Pesquisa do Curso da Ação

\section{0 : a Pandemia da Covid-19 e o mundo do trabalho : um olhar a partir dos setores subalternos}

2020 : Pandemia por covid-19 y mundo del trabajo : una mirada desde los sectores subalternos

Jairo Ernesto Luna-García e Mauricio Torres-Tovar

\section{OpenEdition}

\section{Journals}

\section{Edição electrónica}

URL: http://journals.openedition.org/laboreal/17438

DOI: $10.4000 /$ laboreal. 17438

ISSN: 1646-5237

\section{Editora}

Universidade do Porto

\section{Refêrencia eletrónica}

Jairo Ernesto Luna-García e Mauricio Torres-Tovar, « 2020 : a Pandemia da Covid-19 e o mundo do trabalho : um olhar a partir dos setores subalternos », Laboreal [Online], Volume 16 No2 | 2020, posto online no dia 01 dezembro 2020, consultado o 13 dezembro 2020. URL : http://

journals.openedition.org/laboreal/17438; DOI : https://doi.org/10.4000/laboreal.17438

Este documento foi criado de forma automática no dia 13 dezembro 2020

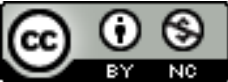

Laboreal está licenciado com uma Licença Creative Commons - Atribuição-NãoComercial 4.0 Internacional. 


\title{
2020 : a Pandemia da Covid-19 e o mundo do trabalho : um olhar a partir dos setores subalternos
}

\author{
2020 : Pandemia por covid-19 y mundo del trabajo : una mirada desde los
} sectores subalternos

Jairo Ernesto Luna-García e Mauricio Torres-Tovar

\section{NOTA DO EDITOR}

Traducción : Fernanda Romero [fernandaromero.trad@gmail.com]

1 Após um ciclo de conferências com oradores de diversas regiões do mundo [1] que abordaram como tema central a situação da saúde dos trabalhadores e trabalhadoras em tempos de pandemia, há espaço para algumas reflexões em relação ao impacto da pandemia da Covid-19 no mundo do trabalho e a resposta que as organizações sindicais têm vindo a dar a esta situação.

\section{Uma experiência global : nem todos atravessam a tempestade no mesmo barco}

2 Um primeiro elemento a salientar é a rápida propagação que teve esta pandemia e o amplo grau de afetação dos territórios e das populações, revelando-se numa experiência partilhada praticamente pelo conjunto dos membros da espécie humana.

Contudo, os diferentes grupos sociais não vivenciam da mesma maneira a atual situação, verificando-se grandes diferenças no Norte Global relativamente ao Sul Global. Ainda que a manifestação da pandemia exprima, num primeiro momento, as centralidades e os vínculos internacionais, em que os portadores ativos se encontram nos setores mais estreitamente ligados à mobilidade internacional (sobretudo aérea), 
grupo em que há uma maior representação de elites, foram os setores subalternos os mais fortemente afetados após a instalação da pandemia nos territórios.

Deste modo, a pandemia põe a nu as desigualdades resultantes da divisão internacional do trabalho, mas também as derivadas das estruturas classistas, sexistas e racistas, que resultam numa maior mortalidade entre as pessoas dos setores empobrecidos, tanto no Norte como no Sul do planeta, ainda que com maior gravidade neste último.

\section{A pandemia e o mundo do trabalho: a tecnologia e as desigualdades que se aprofundam}

5 Não obstante se sustente que a ação face à pandemia tem sido desigual nos diferentes países e que houve uma atitude de negação entre os empresários e os governos que incidiu no atraso na adoção de medidas de intervenção, apresentando-se este problema com maior gravidade em alguns destes países, existe uma grande similitude no tipo de respostas face à situação. Particularmente nos períodos de quarentena, a segmentação da população trabalhadora de acordo com as suas condições de emprego e a possibilidade de adaptar a atividade laboral à utilização das tecnologias de informação e comunicação (trabalho à distância), mostra condições muito distintas :

6 Em primeiro lugar, grandes grupos de trabalhadores e trabalhadoras da economia informal do Sul Global foram confrontados com o dilema de cumprir as medidas de isolamento e ficarem sujeitos a condições de fome, face à ausência ou à cobertura limitada de programas de proteção social que pudessem garantir a satisfação das suas necessidades durante o confinamento.

7 Em segundo lugar, os trabalhadores em situação de emprego formal foram classificados como trabalhadores essenciais e não essenciais, apesar do apelo de um grupo de peritos das Nações Unidas para considerar todos os trabalhadores como essenciais, reconhecendo a importância do trabalho para a existência da sociedade. As medidas de proteção para os que continuaram a trabalhar durante a quarentena variam consideravelmente entre o Norte e o Sul Global. Do mesmo modo, o regresso ao trabalho dos trabalhadores considerados não essenciais após o abrandamento das medidas de confinamento, apresenta também condições muito dissemelhantes nas duas regiões, sempre em detrimento dos que vivem na região do planeta com os níveis de exploração mais elevados.

8 Em terceiro lugar, uma parte importante das atividades laborais do planeta foi realizada remotamente ou a partir de casa durante este período, afetando de maneira ostensiva a relação trabalho-família. Os estudos que foram levados a cabo em alguns países fazem referência a fenómenos de extensão e intensificação das atividades laborais, frequentemente sem que tenha sido apresentada a adequação dos postos de trabalho ou o fornecimento de elementos por parte dos empregadores. Aqui, também os recursos com os quais os trabalhadores e as trabalhadoras contam manifestam as diferenças nas condições de vida entre regiões, países, zonas urbanas e rurais, e classes sociais, sendo que as desigualdades são por sua vez incrementadas como resultado das solicitações derivadas do encerramento dos espaços educativos e de cuidados, situação que vai gerar uma sobrecarga, especialmente para as mulheres.

9 Por último, tornou-se evidente a existência de uma parte significativa da população que é, em grande medida, prescindível para o funcionamento da economia capitalista, as 
pessoas que se encontram em situações mais precárias e que desenvolvem atividades presenciais não essenciais, onde o desemprego e a diminuição drástica dos rendimentos se generalizou. Para este grupo, a pandemia teve os maiores custos em termos de sofrimento e perda de vidas e prova como foram pouco eficazes os apelos vazios à solidariedade internacional e o grande desprezo do capital por aqueles que não lhe são rentáveis. A expressão de alguns poucos protestos sociais não se compadece com a gravidade da situação.

\section{A resposta da força de trabalho: o papel dos sindicatos}

\section{sindicatos, dependendo da força que estes têm nas diferentes regiões e atividades} económicas. No caso da Europa, menciona-se que no tempo decorrido no presente ano se assistiu a uma importante reivindicação de garantias em matéria de proteção da saúde face à pandemia, evidenciando um debate relacionado com a organização do trabalho que confronta a perspetiva higienista que omite as implicações da biossegurança em diferentes contextos de trabalho [2].

11 Nos Estados Unidos, este período foi acompanhado da presença de um movimento grevista que reivindica mais garantias laborais e proteção contra os riscos associados à realização de atividades laborais no quadro da pandemia, juntamente com a procura de um maior reconhecimento económico para a população trabalhadora pertencente ao grupo das atividades essenciais [3].

No Sul Global, a incidência dos sindicatos é menor devido a importantes restrições no exercício da liberdade sindical, mas também como consequência do menor peso do emprego formal. Aqui, vale a pena ressaltar a ação dos sindicatos que reúnem os trabalhadores e trabalhadoras da saúde cujas condições de emprego e de trabalho se vinham já tornando cada vez mais precárias e sobre os quais recaiu um importante papel para enfrentar a crise da pandemia. A ação, impulsionada pelos Serviços Públicos Internacionais (ISP) [4], permitiu não só estimular e coordenar esforços face à garantia de proteção deste importante grupo, mas também confrontar as péssimas condições de emprego em que estes profissionais exercem o seu trabalho. Também se destacam alguns exercícios implementados pelos próprios sindicatos dos profissionais da saúde para monitorizar as condições de trabalho, de bioproteção, de contágio e de morte por Covid-19 dos trabalhadores do setor da saúde, procurando denunciar e exigir aos governos uma atuação para proteger a vida dos que se encontram na linha da frente da pandemia.

\section{A Covid-19 como doença ou acidente de trabalho}

13 Outra dimensão exposta pela crise foi a diversidade de modelos de proteção social existentes em todo o mundo e, por conseguinte, as grandes diferenças em termos de cobertura para garantir prestações sociais e pecuniárias em caso de infeção pelo SARSCoV-2 no trabalho.

14 Numa parte significativa dos países do Norte Global, a doença por coronavírus foi incluída como acidente de trabalho ou doença profissional, tanto para os trabalhadores

Laboreal, Volume $16 \mathrm{~N}^{\circ} 2$ | 2020 
da saúde como para aqueles enquadrados nos setores essenciais, enquanto que nos países do Sul Global a situação é muito heterogénea: em alguns países não foi reconhecida, noutros foi reconhecida parcialmente para os trabalhadores da saúde e em poucos foi reconhecida de uma forma abrangente.

As estatísticas permitem identificar que, no que concerne à população em idade ativa, é possível identificar a profissão como principal fonte de contágio, porém, as garantias de proteção são significativamente diferentes. Como resultado deste facto, não só se apresenta uma possibilidade diferente de se proteger, como também uma probabilidade diferente de ficar doente e aceder aos serviços de cuidados de saúde e à cobertura das prestações pecuniárias.

\section{Desigualdades no emprego e no trabalho}

16 A situação atual teve um profundo impacto no mundo do trabalho, afetando negativamente a maior parte da população trabalhadora em diferentes dimensões: perdas de emprego, diminuição dos rendimentos, agravamento dos problemas de saúde relacionados com a organização do trabalho tanto nas atividades presenciais como nas que migraram para as tarefas desenvolvidas em casa ou a distância, aprofundamento das desigualdades relativamente ao reconhecimento da Covid-19 como acidente de trabalho ou doença profissional, entre outras.

17 Ainda que para os empregadores a situação motive pedidos de apoio económico aos governos para proteger os seus negócios e que estes tenham consciência da sua responsabilidade no âmbito da renovação dos preceitos de higiene ao colocar a ênfase nas medidas de auto-bioproteção por parte dos trabalhadores e trabalhadoras, para os sindicatos a confrontação da situação está relacionada com a superação dos problemas estruturais em matéria de desigualdade nas condições de emprego e de trabalho, a defesa do direito à saúde a partir da organização do trabalho para uma prevenção reforçada e a procura de políticas de proteção social universais que garantam plenamente os direitos.

18 Contudo, existe uma dimensão mais geral de toda esta situação que se prende com a presença de benefícios significativos decorrentes da pandemia verificada nos monopólios de tecnologias de informação e de comunicações, no complexo médicoindustrial e no setor financeiro internacional, que perante a necessidade de despesas sociais são favorecidos com o aumento das dívidas públicas para fazer face às despesas no âmbito da emergência.

19 Simultaneamente, outros lesados desta situação são os protestos sociais que ficaram restringidos no quadro das medidas de controlo social apoiadas na necessidade de dar resposta à pandemia. A adoção de estados de exceção e a concentração de poder nos órgãos executivos fez sobressair o importante papel do Estado, mas com um equilíbrio que não se coloca necessariamente a favor dos interesses coletivos.

\section{Colômbia : espelho da crise laboral, sanitária e social}

$20 \mathrm{Na}$ Colômbia, a pandemia, como reflexo do que sucede em muitas latitudes, revelou cruamente as grandes desigualdades sociais, a precariedade do mundo do trabalho e a 
ausência de políticas universais de segurança social, sobretudo no que se refere aos mecanismos de proteção da saúde no trabalho e de proteção económica.

Ainda que o Governo Nacional tenha, no início da pandemia da Covid-19, tomado medidas de isolamento geral obrigatório, a ausência de formas reais de proteção social para o conjunto da população obrigou, sobretudo aos setores económicos informais, que na Colômbia representam, de acordo com os números oficiais, 50 \% da população ativa a trabalhar [5], a sair para procurar o sustento diário, o que incrementou a taxa de contágio por SARS-CoV-2.

22 A esta questão somou-se o desconfinamento geral, seis meses depois da entrada do vírus no território nacional, com o argumento de que a dinâmica económica não podia continuar a ser travada uma vez que poderia produzir consequências ainda mais letais do que a própria pandemia. Esta decisão fez com que o país se situasse entre os primeiros do mundo em termos de taxa de contágio e taxa de mortalidade por Covid-19.

Esta situação, sem qualquer dúvida, teve um maior impacto nos setores sociais subalternos da sociedade. Por um lado, os setores pobres são os que mais sofreram contágios por SARS-CoV-2 e onde se verificaram mais mortes como consequência da Covid-19. Por outro lado, os setores económicos das micro e pequenas empresas e o setor informal são os que mais sofreram estragos e perdas, uma vez que o Governo concentrou as ajudas económicas nos grandes setores empresariais e na banca, deixando os setores mais frágeis da economia à sua mercê, o que levou a que na Colômbia se tenham perdido mais de 5 milhões de postos de trabalho nestes meses de pandemia [6].

No que respeita à proteção da saúde no trabalho, as medidas foram totalmente insuficientes, subordinadas à lógica e ao comportamento das seguradoras de riscos profissionais, as quais não assumiram um papel solidário e de compromisso com a saúde e a vida dos trabalhadores associados, ao sobrepor os seus interesses económicos. A situação mais dramática foi vivida pelos trabalhadores e trabalhadoras da saúde que, na linha da frente nos cuidados durante a pandemia, não trabalharam com protocolos estritos de biossegurança, o que resultou na infeção de mais de 17.000 trabalhadores e trabalhadoras e na morte de 93 [7]. Relativamente a outros setores de trabalhadores essenciais, tal como foram denominados, não se conhece informação precisa, tal como tem acontecido com a maior parte dos trabalhadores informais.

o Governo Nacional, com o objetivo de contrabalançar a situação dramática vivida pelos trabalhadores do setor da saúde, reflexo de anos de precariedade laboral imposta por um sistema de saúde que se foi privatizando paulatinamente desde a sua implementação, através da Lei 100 de 1993, o que fez foi declarar a Covid-19 como doença profissional, mas apenas para os trabalhadores na primeira linha de cuidados durante a pandemia, atribuindo-lhes uma indemnização pecuniária. É claramente uma política que visa trocar a saúde por dinheiro e que não tem efeitos nos problemas estruturais que explicam o grave impacto da pandemia neste setor de trabalhadores.

Por último, é de mencionar que não obstante as restrições em termos de reunião de pessoas e de circulação impostas pela pandemia, ocorreram manifestações de protesto e de luta neste período para denunciar a situação e exigir mudanças de fundo. Os trabalhadores e trabalhadoras da saúde, em particular, organizaram inúmeras ações coletivas, incluindo greves, tendo reativado e renovado formas organizativas, exigindo trabalho digno, estável e condições seguras para a saúde. 

sindical na Colômbia neste período, ainda que este não tenha ficado paralisado nem permanecido em silêncio, ficou muito enfraquecida, pelo que pouco pôde influenciar a orientação das medidas de saúde pública e de proteção social que devem ser aplicadas para enfrentar adequadamente a pandemia.

\section{Não voltar à normalidade, porque o problema era esse}

Deste modo, existe um amplo espectro de implicações da pandemia no mundo do trabalho, em detrimento dos trabalhadores e trabalhadoras, que se expressa de forma desigual nas regiões, entre os países, no que se refere às cidades e às zonas rurais, e entre os sexos e os grupos étnico-raciais, que apelam a colocar em evidência a situação atual e estimular o apoio aos processos de defesa dos direitos coletivos, procurando simultaneamente promover uma mudança nas políticas de proteção social visando uma universalização dos direitos.

Neste quadro, não é possível falar de regresso à normalidade, no entendimento de que é a situação anterior que permite explicar a crise atual, mas o cenário de pós-pandemia exige uma reavaliação das prioridades no sentido de uma reconfiguração de forças que permita apostar num futuro em que a direção para a qual as nossas sociedades se estão a dirigir seja profundamente revista, que supere o mundo do trabalho tóxico em que nos encontramos, recuperando o lugar central do trabalho, mas que ao mesmo tempo recomponha a essência humana do trabalho como cenário de crescimento e emancipação e que valorize a importância da população que produz os verdadeiros valores na sociedade, para que haja realmente um compromisso para com a vida e a saúde dos trabalhadores e trabalhadoras de todo o mundo. Este é o desafio para as pessoas, organizações e setores progressistas, fazer uma solidariedade eficaz que, ao mesmo tempo, é para com o nosso próprio futuro como espécie.

\section{NOTAS}

1. Foram realizadas sete sessões, nas quais participaram 27 oradores oriundos da Europa, América do Norte, América Central e Caraíbas, Região Andina, Cone Sul, África do Sul e Sul da Ásia. As gravações estão disponíveis em https://www.youtube.com/channel/ UC6Uhp4i0929UJDOPKat20kg/videos

2. Ver, por exemplo, https://www.etui.org/publications/essential-unprotected-highly-mobileworkers-eu-during-covid-19-pandemic

3. https://www.coshnetwork.org/coronavirus

4. https://publicservices.international/resources/news/covid-19-emergency--psi-priorities-andperspectives?id=10694\&lang=en

5. https://www.dane.gov.co/index.php/estadisticas-por-tema/mercado-laboral/empleoinformal-y-seguridad-social 
6. https://www.semana.com/nacion/articulo/coronavirus-en-colombia-54-millones-depersonas-perdieron-el-trabajo-en-abril/675140/

7. http://www.ins.gov.co/Noticias/Paginas/coronavirus-personal-salud.aspx

\section{AUTORES}

\section{JAIRO ERNESTO LUNA-GARCÍA}

Universidad Nacional de Colombia, Grupo Salud Ambiental y Laboral - Doctorado Interfacultades en Salud Pública, Cra 45, Bogotá, Colômbia

jelunag@unal.edu.co

MAURICIO TORRES-TOVAR

Universidad Nacional de Colombia, Grupo Salud Ambiental y Laboral - Doctorado Interfacultades en Salud Pública, Cra 45, Bogotá, Colômbia

mhtorrest@unal.edu.co 